\title{
rAed a 4: A New 67-kDa Aedes aegypti Mosquito Salivary Allergen for the Diagnosis of Mosquito Allergy
}

\author{
Zhikang Peng $^{\mathrm{a}, \mathrm{b}}$ Li Caihe ${ }^{\mathrm{a}, \mathrm{b}}$ Andrew N. Beckett ${ }^{\mathrm{a}}$ Qingdong Guan ${ }^{\mathrm{a}}$ \\ Anthony A. James ${ }^{c, d}$ F. Estelle R. Simons ${ }^{a, b}$ \\ Departments of a Pediatrics and Child Health and ${ }^{b}$ Immunology, University of Manitoba, Winnipeg, Man., Canada; \\ Departments of ${ }^{\mathrm{c}}$ Microbiology and Molecular Genetics and ${ }^{\mathrm{d}}$ Molecular Biology and Biochemistry, University of \\ California, Irvine, Calif., USA
}

\section{Key Words}

Aed a 4 - Aedes aegypti $\cdot$ Immunoglobulin E · Mosquito

allergy $\cdot$ Salivary allergen/antigen

\begin{abstract}
Background: Accurate diagnosis of mosquito allergy has been hampered by the laborious task of obtaining mosquito salivary allergens. We have previously studied 3 recombinant (r) Aedes aegypti mosquito salivary allergens: rAed a 1, rAed a 2 and rAed a 3 . Here, we report the expression, purification, identification and evaluation of rAed a 4, a 67-kDa a-glucosidase. Methods: rAed a 4 was expressed using a baculovirus/insect cell system, purified by a combination of anion- and cation-exchange chromatography, and identified by immunoblotting. A. aegypti saliva extract was prepared in our laboratory. An indirect enzyme-linked immunosorbent assay (ELISA) was developed to measure rAed a 4-specific immunoglobulin $\mathrm{E}(\mathrm{lg} \mathrm{E})$ and $\mathrm{lg} G$ antibodies in sera from 13 individuals with a positive mosquito-bite test from a laboratory-reared mosquito. Sera from 18 individuals with a negative bite test served as controls. Results: Purified rAed a 4 bound to the IgE in mosquito-allergic sera, as detected by ELISA and immunoblotting. The binding of rAed a 4 to $\operatorname{lgE}$ could be inhibited in a dose-dependent manner by the ad-
\end{abstract}

dition of an A. aegypti extract. Mosquito-allergic individuals had significantly higher mean levels of $r A e d$ a 4-specific lgE and IgG than controls. Using the mean of the controls \pm 2 SD as a cut-off level, $46 \%$ of the 13 allergic individuals had a positive IgE, while none of the controls was positive $(p<$ 0.001 ). Conclusions: Aed a 4 is a major allergen in mosquito saliva. Its recombinant form has the hydrolase function and can be used for the diagnosis of mosquito allergy.

(c) 2016 S. Karger AG, Basel

\section{Introduction}

Immunologic reactions to mosquito bites involve mosquito saliva-specific immunoglobulin E (IgE), IgG and cell-mediated hypersensitivity [1,2]. The lack of readily available, specific, sensitive and safe tests for mosquito allergy is a major obstacle to accurate diagnosis.

Currently available mosquito whole-body extracts contain many extraneous proteins that are not present in mosquito saliva [3]. Immunoassays utilizing mosquito saliva as the allergen have significantly higher sensitivity and specificity for the diagnosis of mosquito allergy than those utilizing mosquito whole-body extract [4]; however, collecting mosquito saliva is labor-intensive and im-

\section{KARGER}

E-Mail karger@karger.com

www.karger.com/iaa
(C) 2016 S. Karger AG, Basel

1018-2438/16/1703-0206\$39.50/0
Correspondence to: Dr. Zhikang Peng

Department of Immunology, University of Manitoba

532-715 McDermot Avenue

Winnipeg, MB R3E 3P4 (Canada)

E-Mail zpeng@umanitoba.ca 
practical [3]. Utilization of molecular techniques to clone and express pure mosquito salivary allergens thus has considerable diagnostic and therapeutic potential [5].

The saliva of an adult female Aedes aegypti mosquito contains up to 55 proteins coded by salivary-gland-specific transcripts [6]. At least 10 of these proteins have been identified as allergens [7]. We previously cloned/expressed, purified, identified and evaluated 3 recombinant (r) A. aegypti mosquito salivary proteins in humans: rAed a 1 (68 kDa, apyrase) [8], rAed a $2(37 \mathrm{kDa}, \mathrm{D} 7)$ [9], and rAed a $3(30 \mathrm{kDa}$, also called Aegyptin) [10] that are potentially useful in skin tests and the measurement of mosquito-specific IgE antibodies in serum.

Alpha-glucosidase from the adult salivary glands of $A$. aegypti is a $67-\mathrm{kDa}$, soluble glycoprotein that is secreted when mosquitoes take sugar and blood meals $[11,12]$. In the present study, we expressed the a-glucosidase using a baculovirus/insect cell system, purified and characterized it and then explored its value in the in vitro diagnosis of mosquito allergy using an enzyme-linked immunosorbent assay (ELISA). In accordance with allergen nomenclature, this $\alpha$-glucosidase was named Aed a 4 . This nomenclature was accepted by the World Health Organization and International Union of Immunological Societies (WHO/IUIS) Allergen Nomenclature Subcommittee [13].

\section{Material and Methods}

\section{Serum Samples}

Thirteen sera from individuals with a positive mosquito bite test from a laboratory-reared mosquito consisting of an immediate wheal or a delayed induration of $\geq 0.3 \mathrm{~cm}^{2}$ and 18 sera from those with a negative mosquito bite test were obtained from our previous study [10].

\section{Construction of Recombinant Baculovirus Transfer Vector and} Generation of Recombinant Baculovirus

The methods have been previously reported [10,14]. Genomic and cDNA clones of the Aed a 4 gene (originally named maltaselike gene) were isolated and sequenced by James et al. [12]. Aed a 4 cDNA cloned as an EcoRI fragment into pEMBL plasmid [12] was provided by Dr. A.A. James, University of California, Irvine, Calif., USA. The $1.83-\mathrm{kb}$ Aed a $4 \mathrm{cDNA}$ fragment was digested from the cloned plasmid pEMBL by EcoRI and then cloned into the pVL1393 transfer vector. The baculoviruses containing Aed a 4 DNA for the expression of the recombinant protein (recombinant virus) were generated by cotransfection of Spodoptera frugiperda Sf9 cells with the recombinant transfer vector using the Bac$\mathrm{N}$-Blue transfection kit (version K). Plaque assays were performed and putative recombinant virus DNAs were prepared according to the manufacturer's instruction manual. Recombinant baculoviruses were identified by PCR using polyhedrin forward primer:
$5^{\prime}$-TTTACTGTTTTCGTAACAGTTTTG- $3^{\prime}$ and reverse primer: 5'-CAACAACGCACAGAAATCTAGC-3' followed by PCR reactions. PCR products were analyzed and only pure recombinant viruses that contained the expected DNA fragment were selected as recombinant virus stock.

\section{Expression and Purification}

To increase the yield of expressed products, High Five cells (originated from the ovarian cells of the cabbage looper, Trichoplusia ni) purchased from Invitrogen (San Diego, Calif., USA) grown in Express Five SFM serum-free medium were used [10, 14]. Purification of rAed a 4 from culture supernatants was performed by a combination of anion- and cation-exchange chromatography [14]. Proteins bound to a DEAE-Sephacel column were eluted with a linear $\mathrm{NaCl}$ gradient from 0 to $0.65 \mathrm{M}$ in sodium phosphate buffer. Fractions were collected and assayed for protein concentration using the Bio-Rad protein assay and for $r$ Aed a 4 content using a hydrolase assay. Fractions containing rAed a 4 were pooled, dialyzed, centrifuged and loaded onto a CM-Sepharose column. Bound proteins were eluted with a linear $\mathrm{NaCl}$ gradient from 0 to $0.65 \mathrm{M}$. Fractions containing rAed a 4 were pooled, concentrated and subjected to SDS polyacrylamide gel electrophoresis (SDSPAGE) for purity identification.

\section{Hydrolase Assay}

Aed a 4 is an $\alpha$-glucosidase [11]. The activity of $\alpha$-glucosidase was determined by the release of $p$-nitrophenolate from p-nitrophenyl-a-D-glucopyranoside (pNPG). Fifty microliters of $0.1 \mathrm{M}$ sodium phosphate buffer ( $\mathrm{pH} 7.0)$ containing $10 \mu \mathrm{M}$ pNPG, were added into each well of a 96-well, flat-bottomed microplate; $10 \mu \mathrm{l}$ of test sample was added and mixed. About 20 min later, the plate was read at $410 \mathrm{~nm}$.

\section{Western Blot}

To study whether rAed a 4 bound to the IgE in human mosquito-allergic serum, Western blot was performed using the materials and methods previously reported $[10,14]$. Mosquito saliva was used as a positive control.

\section{ELISA and ELISA Inhibition Test}

ELISAs were developed to detect rAed a 4-specific IgE and IgG according to our previously reported Materials and Methods [14, 15]. In brief, microtiter plates, coated with $0.2 \mu \mathrm{g} /$ well of purified rAed a 4 were incubated with human sera (diluted 1:20 for IgE assay and 1:200 for IgG assay). The bound serum rAed a 4-specific IgE was detected by serial incubations with goat IgG against human IgE, alkaline phosphatase-conjugated rabbit anti-goat IgG and an alkaline phosphatase substrate solution. The bound specific IgG was detected by incubations with monoclonal anti-human IgG, alkaline phosphatase-conjugated goat anti-mouse IgG, and the substrate solution.

An inhibition test was performed to examine whether the binding of human IgE to rAed a 4 could be inhibited by natural Aed a 4 in a mosquito extract and also to determine the specificity of the rAed a 4 -specific IgE assay $[10,14]$.

\section{Statistical Analysis}

Using GraphPad Prism software, unpaired Student's t tests were used for between-group comparisons and the $\chi^{2}$ test was used to compare the positive percentages between groups. 


\section{Results}

\section{Construction and Generation of Recombinant Virus}

Forty-four putative recombinant plaques were finally selected and viral DNAs were prepared. Three pure rAed a 4 virus plaques were confirmed by PCR analysis and used for the expression of rAed a 4 using High Five cells.

\section{Purification}

rAed a 4, adsorbed by the DEAE-Sephacel matrix, was eluted at $0.3-0.4 \mathrm{M} \mathrm{NaCl}$ with other proteins (fig. 1a). As the pooled fraction (fractions 25-30) was still contaminated with other proteins, CM-Sepharose chromatography was utilized for further purification. Almost all the contaminating proteins were excluded from the a-glucosidase functional peak that corresponded well with the protein peak (fig. 1b). rAed a 4 was eluted at $0.3-$ $0.4 \mathrm{M} \mathrm{NaCl}$. Fractions 26-34 were pooled, concentrated to a final protein concentration of $2.5 \mathrm{mg} / \mathrm{ml}$ and subjected to SDS-PAGE. SDS-PAGE results indicated that the purified rAed a 4 showed one single $67-\mathrm{kDa}$ band (fig. 1c).

\section{Identification}

Both natural Aed a 4 in mosquito saliva and purified rAed a 4 bound to the IgE in pooled sera from mosquitoallergic individuals, confirming that these 2 forms have the same allergenicity (fig. 1d).

In the ELISA inhibition test, the binding of serum Aed a 4 -specific IgE to rAed a 4 was successfully inhibited by

Fig. 1. Purification and identification of rAed a 4. a DEAE-Sephacel chromatography. The concentrated rAed a 4 supernatant was dialyzed against sodium phosphate buffer and then loaded onto a DEAE-Sephacel column. After washing the column with the same buffer, the bound proteins were eluted with a linear gradient of $\mathrm{NaCl}$ from 0 to $0.65 \mathrm{M}$ in $20 \mathrm{mM}$ sodium phosphate ( $\mathrm{pH}$ 8.0). Fractions were collected and assayed for proteins concentration using the Bio-Rad protein assay $\left(\mathrm{OD}_{595} \mathrm{~nm}\right.$ was read) and for the rAed a 4 content using the hydrolase assay $\left(\mathrm{OD}_{410} \mathrm{~nm}\right.$ was read). b CMSepharose chromatography. The pooled fraction containing rAed a 4 was loaded onto a CM-Sepharose column. The bound proteins were eluted with a linear gradient of $\mathrm{NaCl}$ from 0 to $0.65 \mathrm{M}$ in 20 $\mathrm{mM}$ sodium phosphate ( $\mathrm{pH}$ 6.5). Fractions were collected, assayed and pooled as above. c SDS-PAGE. d Western blot. After gel electrophoresis separation, proteins in A. aegypti saliva (lane 1) and purified rAed a 4 (lane 2) were transferred to a nitrocellular membrane. The membrane was immunoblotted with a pooled mosquito-allergic human serum, followed by incubation with monoclonal anti-human IgE as described in Material and Methods. the addition of mosquito head and thorax extracts in a dose-dependent manner (data not shown), indicating that the rAed a 4 and the native Aed a 4 in these extracts have identical allergenicity and that the rAed a 4 capture-ELISA is specific for the detection of Aed a 4 -specific IgE in human serum.

\section{rAed a 4-Specific IgE and IgG}

The mean levels of rAed a 4-specific IgE ( $p<0.0079$ and $\operatorname{IgG}(\mathrm{p}<0.004)$ were significantly higher in allergic individuals $(n=13)$ than in controls $(n=18)$ (fig. 2a). Us-

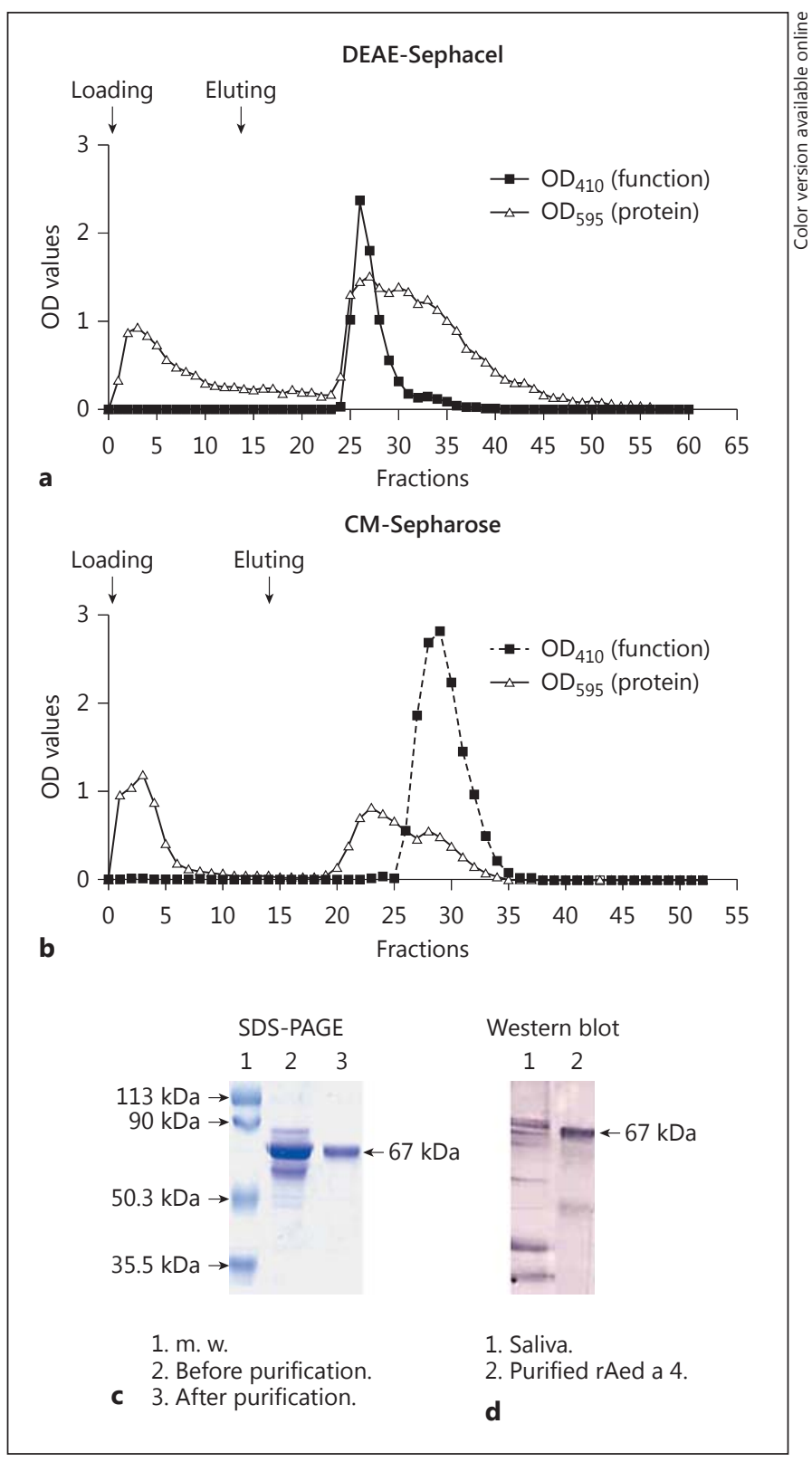


ing the mean of the controls \pm 2 SD as a cut-off level, $46 \%$ of the 13 allergic individuals had a positive rAed a 4-specific IgE and none of the controls was positive ( $\mathrm{p}<0.001$; fig. 2b). In the positivity of rAed a 4 -specific IgG, there was no statistical significance between the 2 groups $(p>0.05)$.

\section{Discussion}

The purified rAed a 4 was shown to bind IgE in the sera of mosquito-allergic subjects, as measured by ELISA and immunoblot analysis. The binding of rAed a 4 to $\operatorname{IgE}$ could be inhibited by the addition of natural Aed a 4 present in the mosquito head and thorax extracts. The hydrolase assay indicated that rAed a 4 functions as a glucosidase. Taken together, these results indicate that rAed a 4 has identical allergenicity and biological activity to its natural form. Also, mean levels of rAed a 4-specific IgE and IgG were significantly higher in mosquito-allergic individuals than in controls.

Aed a 4 is an a-glucosidase that is secreted when mosquitoes ingest sugar or blood. As all mosquito species ingest sugar and blood, Aed a 4 might be possibly be a crossreactive allergen with other mosquito species; indeed, a similar $\alpha$-glucosidase has been found in other mosquito species [16]. This is further supported by the results of this study, in which rAed a 4 bound to the IgE of mosquito-allergic individuals living in Manitoba where A. aegypti is not distributed [7].

In this study, $46 \%$ of individuals with a positive mosquito-bite test had rAed a 4-specific IgE whereas only $29 \%$ have specific IgE to rAed a 1 [8], $11 \%$ to rAed a 2 [17] and $46 \%$ to rAed a 3 [10] when the mean \pm 2 SD of controls is used as a cut-off level. However, these studies were performed separately. A study to compare the results of serum-specific IgE for each allergen with a mosquito saliva-based ELISA simultaneously is in progress in our laboratory.

We did not perform skin tests with rAed a 4 in this study due to ethical limitations; however, we believe that rAed a 4 is capable of inducing skin reactions as it is also expressed by the baculovirus/insect cell system used to express rAed a 1, rAed a 2 and rAed a 3 and, in addition, has the function of $\alpha$-glucosidase.

In summary, Aed a 4 is an important mosquito salivary allergen. In its recombinant form, it has biological functions and can be used for the confirmation of mosquito allergy.
Fig. 2. Serum rAed a 4-specific IgE and IgG levels and percentages in mosquito-bite test positive and negative individuals. a ELISA levels. Serum rAed a 4-specific IgE and IgG levels were measured using ELISA in 13 individuals with a positive bite test from a laboratory-reared mosquito. Eighteen individuals with a negative mosquito bite test served as controls. Values were expressed as mean \pm SD. b Positivity. The geometric mean of the controls \pm 2 SD was used as a cut-off level.

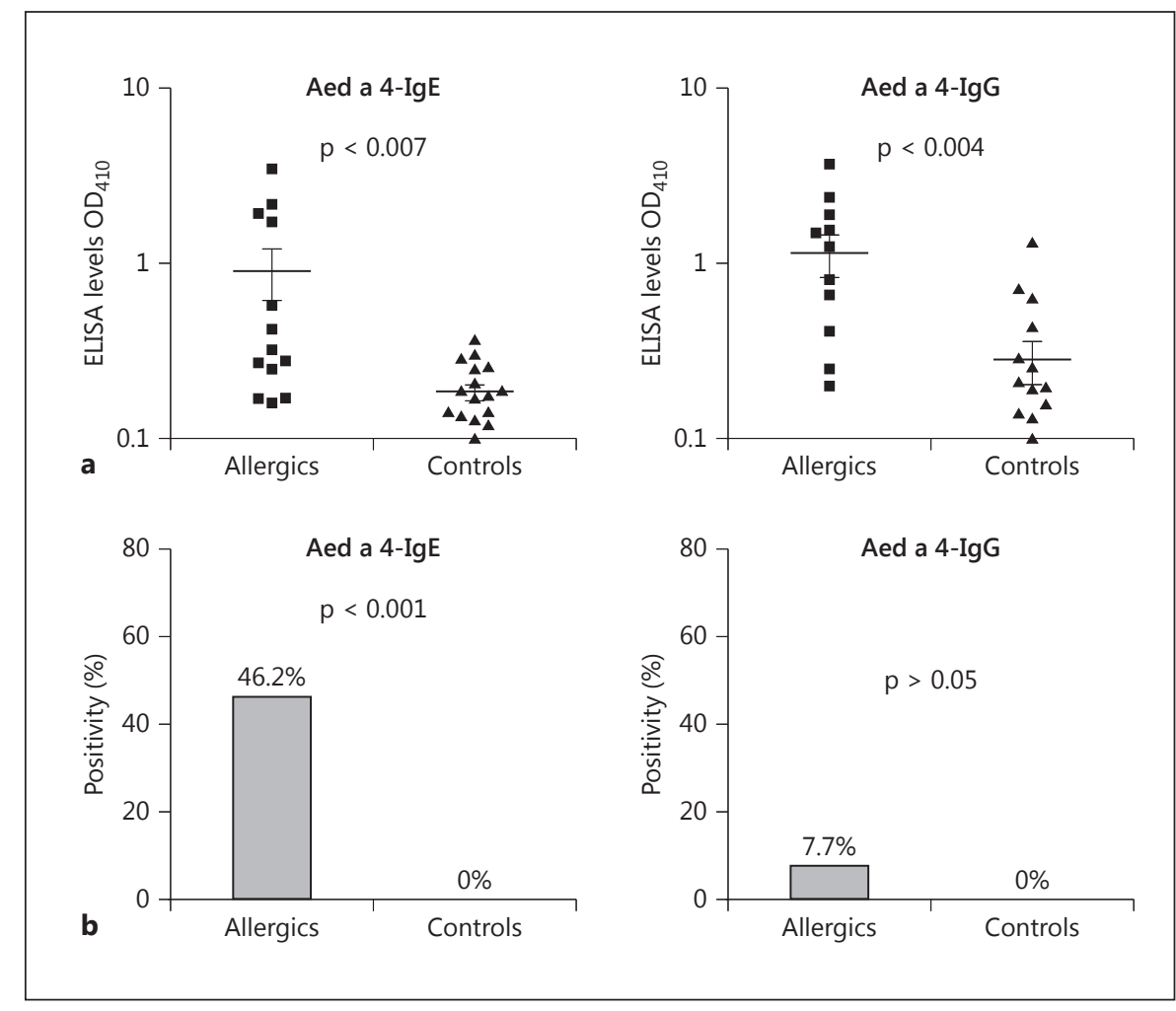




\section{Acknowledgement}

This work was supported by grants from the Children's Hospital Research Institute of Manitoba (CHRIM) in Canada and conducted using the facilities of the CHRIM.

\section{Disclosure Statement}

The authors have declared that no competing interests exist.

\section{References}

1 Peng Z, Simons FER: Advances in mosquito allergy. Curr Opin Allergy Clin Immunol 2007;7:350-354.

2 Peng Z, Beckett AN, Engler RJ, Hoffman DR, Ott NL, Simons FER: Immune responses to mosquito saliva in 14 individuals with acute systemic allergic reactions to mosquito bites. J Allergy Clin Immunol 2004;114:1189-1194.

3 Peng Z, Simons FER: Comparison of proteins, $\mathrm{IgE}$, and IgG binding antigens, and skin reactivity in commercial and laboratory-made mosquito extracts. Ann Allergy Asthma Immunol 1996;77:371-376.

4 Wang Q, Beckett A, Simons FER, Peng Z: Comparison of the mosquito saliva-capture enzyme-linked immunosorbent assay and the UniCAP test in the diagnosis of mosquito allergy. Ann Allergy Asthma Immunol 2007;99: 199-200.

5 Valenta R, Linhart B, Swoboda I, Niederberger V: Recombinant allergens for allergenspecific immunotherapy: 10 years' anniversary of immunotherapy with recombinant allergens. Allergy 2011;66:775-783.

6 Ribeiro JM, Arca B, Lombardo F, Calvo E, Phan VM, Chandra PK, Wikel SK: An annotated catalogue of salivary gland transcripts in the adult female mosquito, Aedes aegypti. BMC Genomics 2007;8:6.
7 Peng Z, Li H, Simons FER: Immunoblot analysis of salivary allergens in 10 mosquito species with worldwide distributions and the $\mathrm{IgE}$ responses to these allergens. J Allergy Clin Immunol 1998;101:498-505.

8 Peng Z, Xu W, James AA, Lam H, Sun D, Cheng L, Simons FER: Expression, purification, characterization, and clinical relevance of rAed a $1-\mathrm{a} 68-\mathrm{kDa}$ recombinant mosquito Aedes aegypti salivary allergen. Int Immunol 2001;13:1445-1452.

9 Peng Z, Xu W, Lam H, Cheng L, James AA, Simons FER: A new recombinant mosquito salivary allergen, rAed a 2: allergenicity, clinical relevance, and cross-reactivity. Allergy 2006;61:485-490.

10 Peng Z, Xu WW, Sham Y, Lam H, Sun D, Li C, Rasic NF, Guan Q, James AA, Simons FER: Mosquito salivary allergen Aed a 3: cloning, comprehensive molecular analysis, and clinical evaluation. Allergy 2015;71:621-628.

11 Marinotti O, James AA: An alpha-glucosidase in the salivary glands of the vector mosquito, Aedes aegypti. Insect Biochem 1990;20:619623
12 James AA, Blackmer K, Racioppi JV: A salivary gland-specific, maltase-like gene of the vector mosquito, Aedes aegypti. Gene 1989; 75:73-83.

13 Radauer C, Nandy A, Ferreira F, Goodman RE, Larsen JN, Lidholm J, Pomes A, RaulfHeimsoth M, Rozynek P, Thomas WR, Breiteneder H: Update of the WHO/IUIS allergen nomenclature database based on analysis of allergen sequences. Allergy 2014;69:413-419.

14 Li C: Expression, purification and characterization of recombinant mosquito salivary allergens for the diagnosis of mosquito allergy; MSc thesis, 2004 (http://mspace.lib.umanitoba.ca/handle/1993/20092)

15 Peng Z, Yang M, Simons FER: Measurement of mosquito Aedes vexans salivary gland-specific IgE and IgG antibodies and the distribution of these antibodies in human sera. Ann Allergy Asthma Immunol 1995;74:259-264.

16 Marinotti O, de Brito M, Moreira CK: Apyrase and alpha-glucosidase in the salivary glands of Aedes albopictus. Comp Biochem Physiol B Biochem Mol Biol 1996;113:675679

17 Simons FER, Peng Z: Mosquito allergy: recombinant mosquito salivary allergens for new diagnostic tests. Int Arch Allergy Immunol 2001;124:403-405. 